\title{
AVALIAÇÃo DE DESEMPENHO ESCOLAR
}

O objetivo desse documento é destacar alguns conceitos de medida relacionados à avaliação do desempenho escolar no Estado de São Paulo. É importante considerar a avaliação do desempenho escolar como um sistema de instrumentos de avaliação e deixar claro o objetivo, ou os objetivos, do sistema de avaliação. Com essa finalidade, discutirei primeiramente alguns objetivos que a Secretaria Estadual de Educação pode ter considerado em relação ao sistema de avaliação de desempenho escolar. Instrumentos de avaliação diferentes são indicados para objetivos diferentes, portanto vou incluir algumas características dos instrumentos de avaliação para cada objetivo abordado. A Secretaria Estadual de Educação pode ter outros objetivos em relação à avaliação do desempenho escolar. Espero que esse documento possa ajudar na identificação desses outros objetivos para que possam ser considerados no planejamento do sistema de avaliação. Estatísticas e questões de avaliação também influenciam o signifi-cado dos resultados de um sistema de avaliação. Algumas dessas questões são abordadas no final do documento.

\section{OS RESULTADOS DA AVALIAÇÃo DE DESEMPENHO ESCOLAR}

Os resultados da avaliação de desempenho escolar são fragmentos de informação que podem ser utilizados para a tomada de decisões ou a emissão de julgamentos. A informação não indica necessariamente qual a medida mais apropriada que deve ser adotada após a análise dos resultados da avaliação. Como qualquer informação utilizada na tomada de decisões, os resultados obtidos a partir de instrumentos de avaliação devem ser

* Educational Testing Service 
apreciados para determinar a sua utilidade na tomada de decisōes relativas às ações que serão desempenhadas. Em outras palavras, as avaliações geralmente não indicam as causas; o fato de um grupo de alunos ser melhor que outro não indica por quê esses alunos são melhores. Informações externas ao teste do aluno, como os estudos qualitativos, podem fornecer algumas pistas sobre os motivos que levam um grupo a ser melhor que outro. No entanto, somente um estudo experimental poderá indicar precisamente por que um grupo é de fato melhor.

\section{O Público}

Para centralizar minha decisâo nos objetivos da avaliação de desempenho escolar é preciso considerar o público que pode estar interessado nos resultados de um sistema de avaliação. Como indica o documento $O$ sistema de avaliação de desempenho escolar, o público interessado na utilização dos resultados é grande e variado. A Secretaria Estadual de Educação, os membros da equipe técnica da SEE, as equipes das Delegacias de Ensino, os diretores de escolas, os professores e coordenadores, os pais e o público em geral são públicos em potencial. Cada uma dessas pessoas tem interesses particulares e comuns. Os tipos de informação do interesse de cada um desses públicos é determinado pelo seu papel no sistema educacional. A SEE é responsável pelas medidas políticas relativas à educação. A equipe técnica da SEE tem interesse especial nos diferentes aspectos da reforma educacional. As equipes das Delegacias de Ensino têm a obrigação de dar apoio às equipes escolares para que estas possam melhorar o ensino. Os diretores e coordenadores fornecem o apoio aos professores que estão diariamente e a toda hora em contato com as crianças. Devido à relação contínua com as crianças, os professores e as famílias devem ser o ponto central do processo educacional. As famílias também podem participar das decisões que são tomadas na escola através do contato com os diretores e coordenadores. O público em geral tem um interesse econômico pois quer garantir que os alunos que freqüentam as escolas irăo adquirir certas habilidades que são fundamentais.

\section{Os OBJETIVoS DA AVALIAÇÃo DE DESEMPENHO ESCOLAR}

Diferentes tipos de decisôes podem ser tomadas baseadas nos resultados das avaliaçōes. As decisões podem estar diretamente relacionadas ao ensino dos alunos, tais como as decisões sobre a efetividade da experiência de ensino. Na minha opinião, esses são os mais importantes tipos de decisões que podem ser influenciados pelas avaliações de desempenho escolar. Se 
não há uma avaliação objetiva do ensino dos alunos nas salas de aula, essa deverá ser a primeira prioridade de qualquer sistema de avaliação.

As informações provenientes de avaliações podem auxiliar nas decisỗes sobre a promoção, o grau de ensino ou a formação do aluno. As avaliações mostram se um professor deve ser contratado novamente, se merece um salário mais elevado, ou se deve ser transferido para outra classe. As avaliações mostram se o diretor está fazendo um bom trabalho ou não. As avaliaçöes fornecem informaçōes que podem ser usadas pelos pais para ajudá-los a escolher a escola de seus filhos. As avaliações podem dar uma indicação sobre o tipo de escola que é mais adequado para certas crianças. Essas decisões geram consequiências para os alunos, os professores, os diretores e o pessoal da escola que está sendo julgada. Por esse motivo, as avaliações usadas de acordo com esses objetivos devem ser confiáveis. Quando as pessoas säo diretamente influenciadas por julgamentos baseados em avaliações, elas estarão altamente motivadas mas estaräo também inclinadas a tentar fazer a avaliação parecer o mais positiva possível. Quando os alunos estão sendo julgados, um cuidado especial deve ser tomado para que os professores não ensinem "em função do teste"ou não cometam erros na realização do teste.

As avaliações podem fornecer informações que implicam em decisões políticas. Nesse contexto, é difícil motivar os alunos em relação à realização dos testes e os professores e escolas em relação à participação na avaliação. Por outro lado, a segurança do teste não será uma questão importante se os alunos e os educadores não enxergarem uma influência direta sobre eles mesmos.

\section{A AVALIAÇĀo de deCisốES POLÍTICAS}

$\mathrm{Na}$ tomada de decisões políticas, há dois aspectos relativos às avaliações que devem ser considerados. O primeiro é uma questão estatística e prática: uma pesquisa aleatória pode ser realizada com precisão? Na melhor das hipóteses, uma pesquisa aleatória pode indicar que influência uma certa decisão política tem sobre o desempenho da escola. Na prática, no entanto, raramente decisões políticas podem ser instituídas aleatoriamente. Isso significa que o resultado de uma decisão política não é seguro. A questão estatística e prática é que a configuração não-experimental pode dar a melhor indicação do resultado da decisão política ao mesmo tempo que preserva o custo, em termos de tempo, dinheiro e energia da avaliação realizada.

O segundo aspecto das avaliaçôes que precisa ser considerado em relação à tomada de decisões políticas é a identificação da variável de interesse. Em outras palavras, qual sua expectativa em relação à influência da política. A política aumentará a porcentagem de alunos que concluem a 
escola secundária? A política aumentará o número de pontos em um tipo de teste específico? A política aumentará o leque de conhecimentos que os alunos têm?

\section{As Questões eSTatísticas}

A primeira e mais importante questão estatística já foi descrita anteriormente. Que configuração não-experimental deverá ser utilizada para reunir as evidências para a tomada de decisőes a respeito da política em questão? Examinar-se-à uma série de amostras regionais cruzadas ou reunirse-á uma amostra longitudinal? Se quiser saber se a política influenciou os alunos da quarta série (por exemplo) a configuração regional cruzada com comparaçōes de amostras realizadas antes da política ser adotada com amostras realizadas depois da efetivação da política deverá ser a mais adequada. Se quiser saber se essa política atinge os alunos e como estes mudam com o tempo, um estudo longitudinal deverá ser usado. Geralmente, os estudos longitudinais de alunos são mais dispendiosos que os estudos regionais cruzados, mas o que o se deseja saber deve ser considerado prioritariamente.

Outras questões estatísticas aparecem após a escolha de uma configuração não-experimental. Por exemplo, como deverão ser feitas as comparações de alunos no decorrer do tempo de acordo com a configuração escolhida? Que critérios devem ser utilizados para determinar se as mudanças decorrentes da política são significativas?

\section{AS QUESTÕES DE MEDIDA}

A questão de medida mais importante também já foi apresentada. É a definição de seu interesse no que deve ser medido. O que deverá mudar em decorrência das decisões políticas?

Uma vez respondida essa pergunta, a questão como medir de forma mais eficiente o que você acredita que irá mudar torna-se importante. Por exemplo, se você acredita que a capacidade de leitura será afetada, seria adequado dar a cada aluno o mesmo texto e formalizar 10 perguntas ou seria melhor ter várias formas de testes com um grande variedade de textos (digamos, um texto que requer uma interpetração literária, outros que incluam exercícios baseados nas indicações de leitura ou ainda textos que incluem assuntos técnicos). Uma outra questão de medida é como seu teste poderá permanecer atual com novas técnicas e tópicos vistos em sala de aula e continuar medindo as mudanças na capacidade do aluno? Os resultados dos 
testes são influenciados pelos modelos de medidas que estão sendo utilizados para resumir esses resultados? Como as tendências são afetadas pelas lacunas da escala de medida?

\section{Conclusão}

A primeira meta no desenvolvimento de um sistema de avaliação é identificar o objetivo ou os objetivos da avaliação. Um fator integral de identificação do objetivo da avaliação é a identificação do que deve ser medido. Com o objetivo claramente definido e o que deve ser medido claramente estabelecido, uma configuração não-experimental pode ser escolhida para fornecer a melhor informação em relação à questão determinada. Outras questões estatísticas e de medida podem ser resolvidas com consideraçôes cuidadosas em relação ao objetivo da avaliação, o que está sendo medido, e os custos decorrentes de cada configuração específica e das opções de análise. 